\title{
Urban Mining: The Indium Issue
}

\author{
Francisco J Alguacil and Felix A Lopez* \\ National Center for Metallurgical Research (CENIM), Spanish National Research Council (CSIC), Spain
}

Submission: February 19, 2021; Published: March 15, 2021

*Corresponding author: Felix A Lopez, National Center for Metallurgical Research (CENIM), Spanish National Research Council (CSIC), Spain

\section{Abstract}

Indium, and indium-bearing alloys, are components found in a series of electronic devices of widespread use; at the end of this useful life, and due to its price and scarcity, the recovery of this element, from these devices, is of interest. Hydrometallurgical processing can be a solution to match this issue.

Keywords: Indium; E-Wastes; Recovery; Hydrometallurgy; Urban mining

\section{Introduction}

Indium is a metal presenting some special features, alone or combined with Indium Tin Oxide (ITO), which made of it a unique component in a series of electronic equipment's. Indium Tin Oxide (ITO, or tin-doped indium oxide) is a mixture of indium (III) oxide $\left(\mathrm{In}_{2} \mathrm{O}_{3}\right)$ and tin (IV) oxide $\left(\mathrm{SnO}_{2}\right)$, typically $90 \% \mathrm{In}_{2} \mathrm{O}_{3}, 10 \% \mathrm{SnO}_{2}$ by weight. It is transparent and colorless when deposited as a thin film at thicknesses of 1000-3000 angstroms. When deposited as a thin film on glass or clear plastic it functions as a transparent electrical conductor.

The main use of ITO in industry is to create electrodes in the form of thin, transparent films on liquid crystal displays, which can be LCD, OLED, electroluminescent or electrochromatic, as well as many touch screens. ITO is normally deposited by a physical vapor deposition process such as D.C. magnetron sputtering or electron beam deposition [1,2]. ITO is used in several display technologies, such as LCD, OLED, plasma, electroluminescent, and electrochromatic displays, as well as in several touch screen technologies $[3,4]$.

The production of e-Wastes in the world was 53.6Mt in 2019 (quote) (Europe, $12 \mathrm{Mt}$ and Americas $13.1 \mathrm{Mt}$ ). The value of the raw materials contained in e-Wastes is about 57 billion USD. Only $17 \%$ of the world's e-waste production is collected and treated [5]. Given the scarcity of raw materials (indium is usually obtained as a by-product in zinc processing), the production of indium from post-consumer products (urban mining) is becoming an environmentally viable and economically very interesting solution.
The indium recovery process in e-Wastes (LCD, OLED and other screens types) starts with a dismantling stage to obtain the ITO-containing foils (Figure 1a). These sheets are constituted by a quartz layer, sheets of a plastic material and ITO coatings. These sheets ( $1 \mathrm{~mm}$ thickness) are then crushed and ground to obtain a product with a particle size of less than $90 \mu \mathrm{m}$ (Figure 1b). A typical composition of this ground material, in majority elements, expressed in $\mathrm{g} / \mathrm{kg}$ of ground material would be as follows: plastic: 460; $\mathrm{SiO}_{2}: 325 ; \mathrm{Al}_{2} \mathrm{O}_{3}: 62$; $\mathrm{SrO}: 31 ; \mathrm{SnO}_{2}: 1.9 ; \mathrm{In}_{2} \mathrm{O}_{3}: 0.6$. With this second step, a homogeneous material is derived, material which feed a third step of acidic leaching, with the objective to put into solution all the indium contained in the previously obtained concentrate.

It may be clear that indium is not the unique element in the above solution, thus, this multi-elemental solution must be treated to separate indium from the rest of accompanying metals. A typical composition of the solution obtained after leaching, expressed in mg/L, is as follows: In: 9.0; Sn: 9.7; Sr: 93.6 and Fe: 210. A very interesting proposal to achieve this separation is using liquid-liquid extraction technology [6-9]. Nowadays, this industrial technology is used in the hydrometallurgical processing of gold, copper, zinc, cobalt, nickel, etc [10]. In this case, the main steps for the processing will be as:

a) Iron removal from the leaching solution. Basically, this iron appeared from the grind/milling operation.

b) Indium recovery from the raffinate (aqueous solution) derived from the previous step. 
c) Yielding of a new raffinate (second aqueous solution), having not indium, but containing an appreciable strontium concentration, the approach to its recovery may be also of interest.

These steps will be performed with industrial extractants as being solvation reagents, amines and/or their ionic liquid derivatives; the above dissolved in a suitable industrial organic diluent. As an example, the next figure (Figure 2) showed the results derived from the treatment of a real leaching solution derived in the treatment of electronic scraps. It can be observed that using a high $\mathrm{V}_{\mathrm{a}} / \mathrm{V}_{\mathrm{o}}$ (volume of leaching solution/volume of organic) relationship, iron is removed from the leaching solution, and indium (plus hydrochloric acid and strontium) being present in the raffinate.
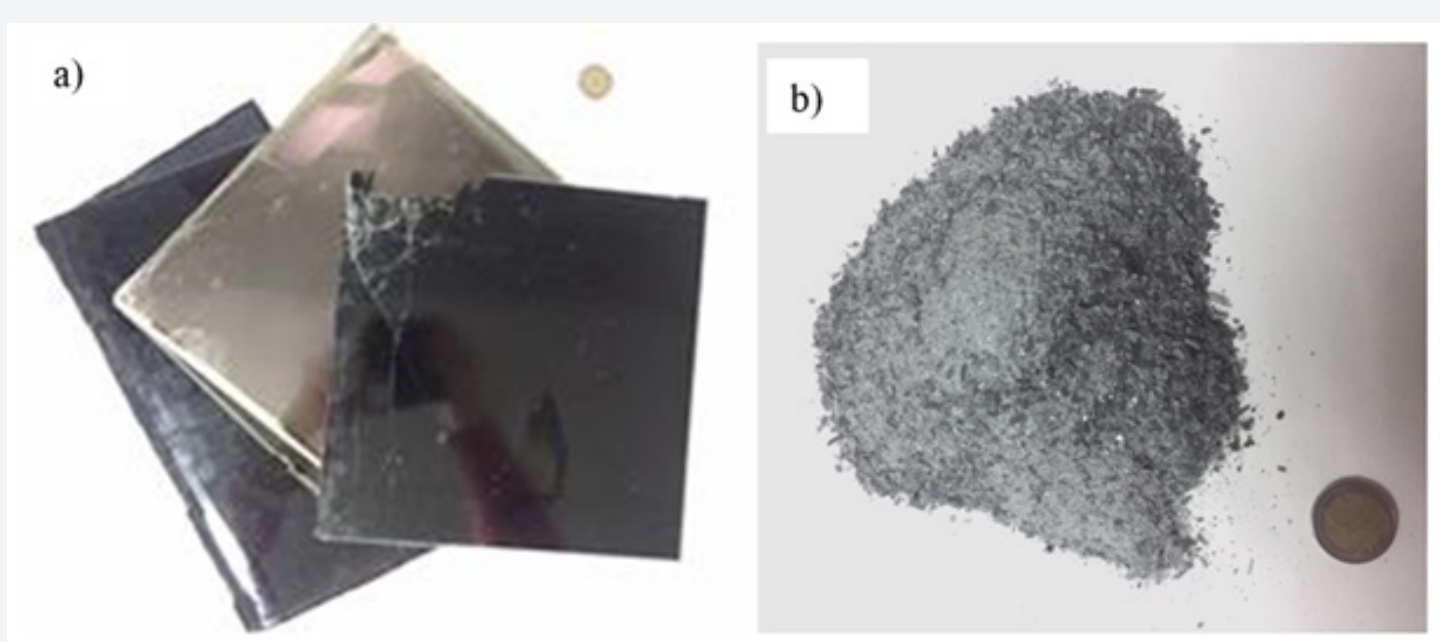

Figure 1: (a) Sheets obtained after selective dismantling of screens and (b) appearance of material obtained after crushing and grinding.

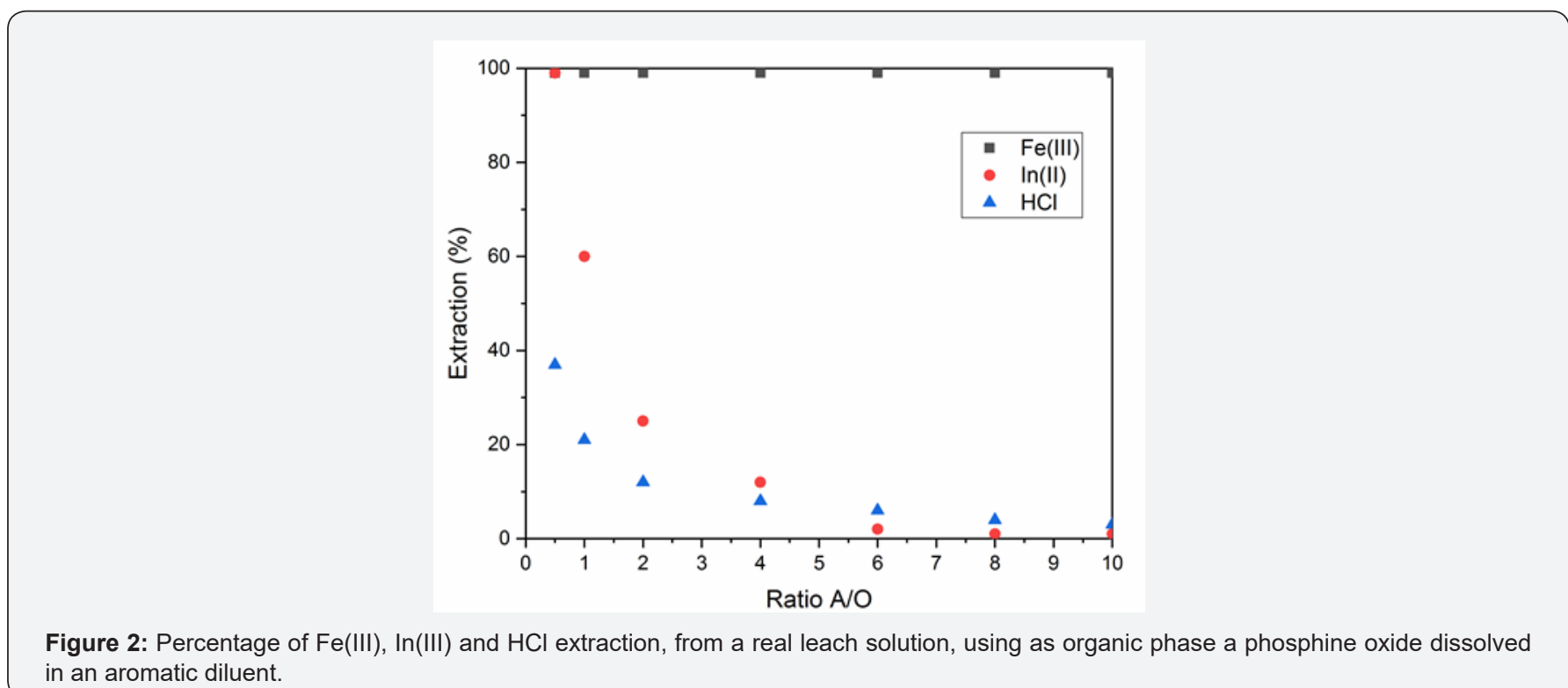

In a second step, using this raffinate and employing a low $\mathrm{V}_{\mathrm{a}} / \mathrm{V}_{\mathrm{o}}$ relationship, indium is almost quantitatively recovered in the organic solution. From this second step, a second raffinate containing strontium is yielded (see point (c) above). In the case of iron and indium, these elements can be stripped from the correspondent organic solution using a suitable strip aqueous phase. Indium can be finally recovered from this solution. The residue from the acid leaching stage, consisting of a mixture of quartz and plastic, is subjected to an electrostatic separation process to obtain an amorphous quartz fraction (Figure 3a) that 
can be reused and a plastic fraction (Figure $3 \mathrm{~b}$ ) that can also be reused for the manufacture of new plastics. This process, which is still in the development phase, would allow full utilization of the materials contained in the screens and is a good example of the application of urban mining concepts to e-wastes.
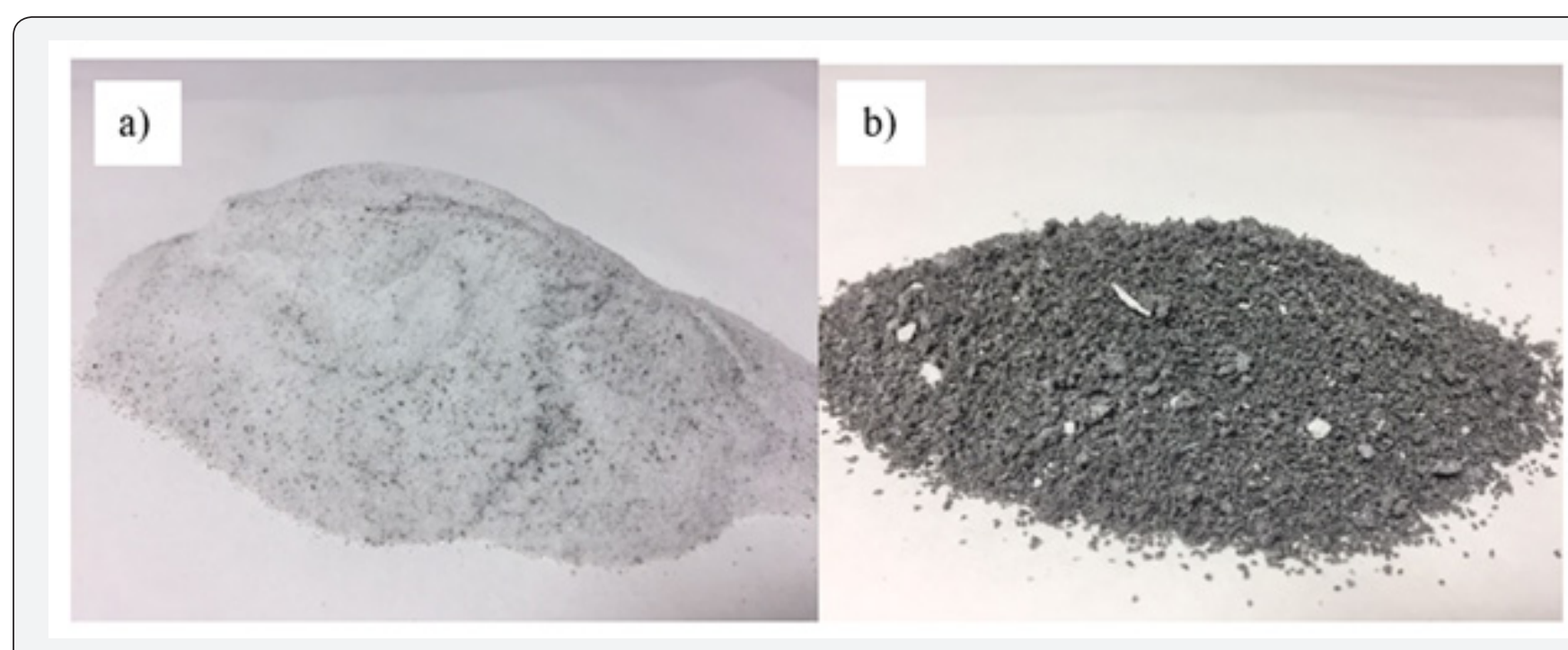

Figure 3: (a) amorphous quartz and (b) plastics fraction.

\section{Conclusion}

Under the concept of urban mining, the use of hydrometallurgical operations can be a solution to the recovery of indium from end-of-life electronic components, making feasible the recycling of this valuable and scarce metal in new products, and extending its useful life.

\section{Acknowledgement}

Our thanks to the Interdisciplinary Platform for Sustainable Plastics towards a Circular Economy (SusPlast) of the Spanish National Research Council (CSIC).

\section{References}

1. Lippens P, Muehlfeld U (2012) Indium Tin Oxide (ITO): Sputter Deposition Processes. Handb Vis Disp Technol Berlin, Heidelberg: Springer Berlin Heidelberg pp. 779-794.

2. Sarakinos K, Martinu L (2020) Synthesis of thin films and coatings by high power impulse magnetron sputtering. High Power Impuls. Magnetron Sputtering, Elsevier pp. 333-374.
3. Lin HW, Chang CP, Hwu WH, Ger MD (2008) The rheological behaviors of screen-printing pastes. J Mater Process Technol 197(1-3): 284-291.

4. Yeom JM, Jung HJ, Choi SY, Lee DS, Lim SR (2018) Environmental Effects of the Technology Transition from Liquid-Crystal Display (LCD) to Organic Light-Emitting Diode (OLED) Display from an E-Waste Management Perspective. Int J Environ Res 12: 479-488.

5. (2020) The Global E-waste Monitor. n.d.

6. Pradhan D, Panda S, Sukla LB (2018) Recent advances in indium metallurgy: A review. Miner Process Extr Metall Rev 39(3): 167-180.

7. Sethurajan M, van Hullebusch ED, Fontana D, Akcil A, Deveci H, et al. (2019) Recent advances on hydrometallurgical recovery of critical and precious elements from end-of-life electronic wastes - a review. Crit Rev Environ Sci Technol 49: 212-275.

8. Ciro E, Dell Era A, Pasquali M, Lupi C (2020) Indium electrowinning study from sulfate aqueous solution using different metal cathodes. J Environ Chem Eng 8(2): 103688.

9. Alguacil FJ, Escudero E (2019) Solvent extraction of indium (III) from $\mathrm{HCl}$ solutions by the ionic liquid $\left(\mathrm{A} 324 \mathrm{H}^{+}\right)\left(\mathrm{Cl}^{-}\right)$dissolved in Solvesso 100. Hydrometallurgy 189: 105104.

10. Regel RM, Alguacil FJ (2013) Recent trends in metals extraction. Rev Metal 49(4): 292-316. 
Your next submission with Juniper Publishers will reach you the below assets

- Quality Editorial service

- Swift Peer Review

- Reprints availability

- E-prints Service

- Manuscript Podcast for convenient understanding

- Global attainment for your research

- Manuscript accessibility in different formats

( Pdf, E-pub, Full Text, Audio)

- Unceasing customer service

Track the below URL for one-step submission https://juniperpublishers.com/online-submission.php 